\title{
Entre plantas e documentos: algumas considerações sobre a contribuição do acervo do IEB ao Pequeno guia da botânica modernista
}

[ Between plants and documents: some considerations on the contribution of the IEB collection to "A guide book of modernist botany"

\section{Ana Carolina Carmona Ribeiro'}

Agradecimentos a Gabriel Pedrosa, Camilla Freitas, Vladimir Bartalini, Elisabete Marin Ribas e Luciana Suarez Galvão.

RESUMO - O artigo apresenta o livro Pequeno guia da botânica modernista, no qual são investigadas I9 das espécies vegetais representadas pelos modernistas de São Paulo. A publicação traz, além de reproduções de obras artísticas e literárias, imagens de documentos históricos pertencentes a diversos arquivos, entre eles o do IEB. Discutiremos as contribuições trazidas por esse acervo, notadamente o do Fundo Mário de Andrade, no qual se encontra um curioso cartão-postal enviado por Oswald a Mário e três fotografias pouco conhecidas tiradas por Mário na viagem à Amazônia em I927. - PALAVRAS-CHAVE . Botânica modernista; divulgação científica; pesquisa em acervos. ABSTRACT - This article presents the publication A guide book of modernist botany, which investigates I9 of the plant species represented by São Paulo's modernist artists. The book includes -- in addition to reproductions of artistic and literary works -- historical documents belonging to various archives, the IEB collection among them. We will discuss these archives' contributions, notably the Mário de Andrade Fund, home to a curious postcard Mario received from Oswald de Andrade as well as three little-known photographs taken by Mário during his 1927 trip to the Amazon. - KEYWORDS - Modernist botany; scientific communication; archive research.

Recebido em 20 de junho de $202 I$

Aprovado em 23 de julho de $202 \mathrm{I}$

RIBEIRO, Ana Carolina Carmona. Entre plantas e documentos: algumas considerações sobre a contribuição do acervo do IEB ao Pequeno guia da botânica modernista. Revista do Instituto de Estudos Brasileiros, Brasil, n. 79, p. I65-I78, ago. 2021.

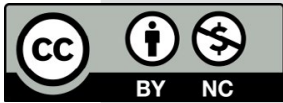

DOI: https://doi.org/Io.II606/issn.23I6-90IX.vIi79pI65-I78

I Universidade de São Paulo (USP, São Paulo, SP, Brasil); Instituto Federal de São Paulo (IFSP, São Paulo, SP, Brasil). 
A ideia de organizar o Pequeno guia da botânica modernista (RIBEIRO, 2020) surgiu durante a pesquisa de doutorado Botânica modernista e a natureza do Brasil redescoberto, um estudo sobre a representação das espécies vegetais no modernismo paulista das décadas de I920 e I930. O principal objetivo do trabalho foi o de esclarecer o papel da vegetação e de categorias afins - como natureza e paisagem - na busca de uma identidade nacional e moderna para o Brasil. Ao analisar obras de artistas como Lasar Segall, Anita Malfatti, Tarsila do Amaral, Flávio de Carvalho, Mina Klabin Warchavchik, Mário de Andrade, Oswald de Andrade, Blaise Cendrars e Paulo Prado, em sua interlocução com obras de autores considerados pré-modernistas, como Monteiro Lobato, e de artistas não expressamente identificados com o movimento paulista, como Manuel Bandeira, Carlos Drummond de Andrade e Roberto Burle Marx, percebemos que, articulando um conjunto significativo de plantas, elas criam novos "símbolos vegetais" e apontam para novas relações entre natureza e cultura. Surgiu assim a expressão "botânica modernista", que continuamos a empregar aqui.

Além dos estudos teóricos e históricos sobre o modernismo de I922 e da análise comparativa das obras, a pesquisa envolveu um extenso "levantamento pictórico-literário” de espécies vegetais. Nele - tal qual um botânico que vai a campo coletar espécies e volta com a sacola cheia -, descobrimos que, surpreendentemente, esses artistas e escritores faziam menção a mais de 200 plantas. Dessas, ao menos 70 apareciam mais de uma vez nas suas obras. Algumas famílias ou espécies eram representadas dezenas de vezes, enquanto outras, apesar de raramente mencionadas, se destacavam como tema principal de ensaios, poemas, pinturas, gravuras e desenhos, sendo utilizadas, ainda, nos primeiros projetos de jardins modernistas. Tal descoberta, aliada à intuição de que tanto a botânica quanto a arte são assuntos que interessam a um público muito mais amplo, para além dos especialistas, fez com que a vontade de tornar a pesquisa mais acessível ganhasse impulso - nascendo então o Pequeno guia, no qual foram apresentadas e discutidas I9 dessas plantas.

Não são apenas plantas nativas, como seria de esperar, mas também plantas exóticas naturalizadas brasileiras; espécies do mundo todo (africanas, como o café, australianas, como o eucalipto), que, da mesma forma que as 
ferrovias, automóveis e arranha-céus, passam a delinear nossa modernidade; espécies do México e da América Central (como o agave), que falam da busca modernista pelas raízes latino-americanas e ancestrais do Brasil, anteriores à colonização; plantas nobres, que servem para embelezar a grande cidade (como as palmeiras e os plátanos); plantas humildes como o milho - carinhosamente chamadas, em Macunaíma (ANDRADE 20I3a), de "plantinhas" ou "plantas boas" -, que alimentam a gente da roça ou da floresta; e até mesmo plantas que, normalmente desprezadas e taxadas de "mato" (a embaúba, a aninga, a tiririca), passam no modernismo a explicitar a dimensão intensa e conflituosa da relação homem-natureza. São árvores, ervas, folhagens e arbustos variadíssimos, que brotam na selva, nas plantações e nos jardins, no solo seco e à beira das lagoas, uns associando-se à volúpia, à exploração e ao desejo de dominação e controle, outros, à fertilidade e à capacidade de resistência.

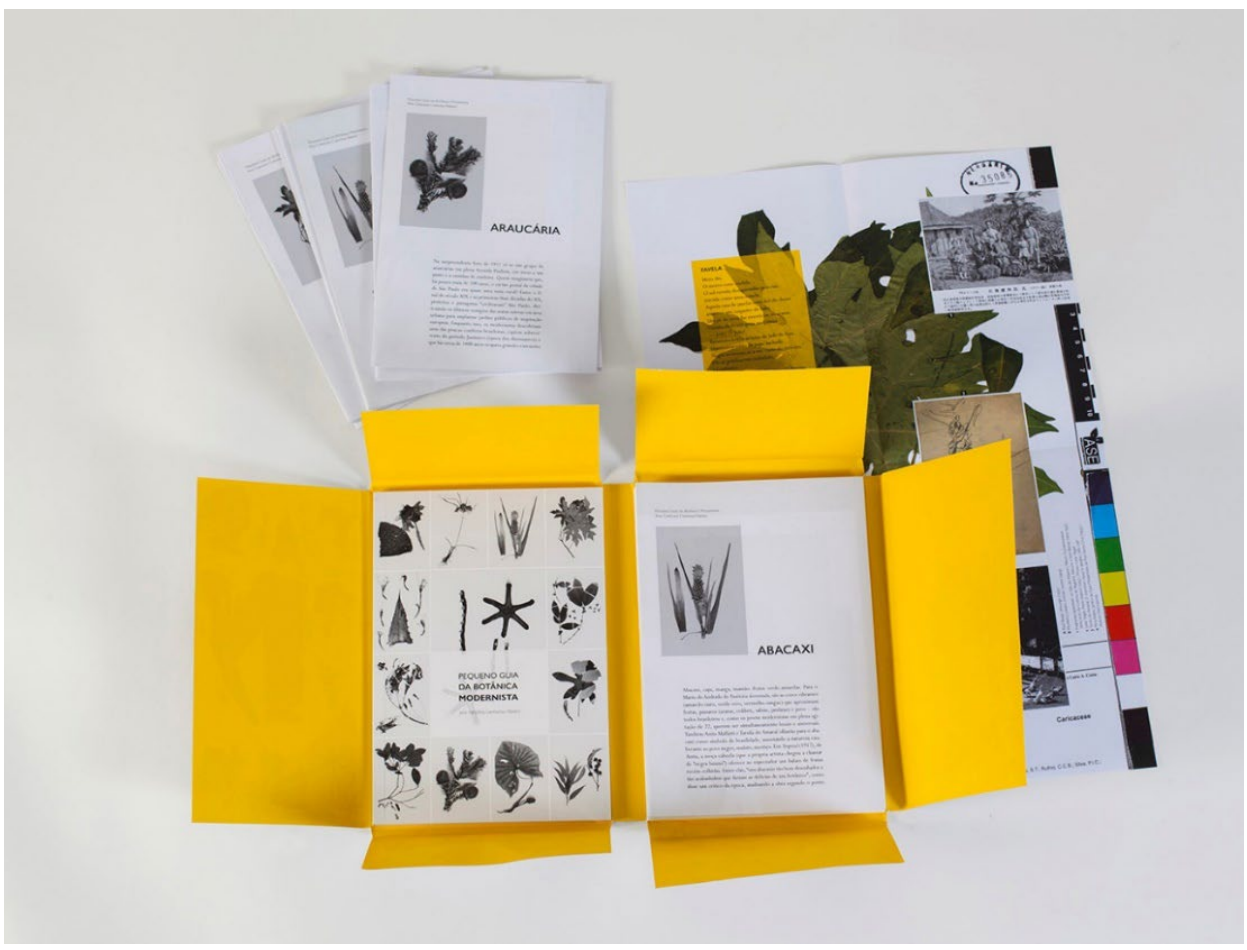

Figura I - Projeto gráfico do Pequeno guia da botânica modernista (projeto gráfico de Gabriel Pedrosa). Fotografia de Tatiana Nolla

Priorizou-se, na publicação, a utilização de materiais e linguagens capazes de despertar a curiosidade dos leitores. Assim, concebido como um livro-objeto, o projeto gráfico do Pequeno guia procurou explorar as múltiplas possibilidades de leitura de cada planta, estimulando a reflexão sobre as relações entre ciência e arte, representação e realidade. De forma lúdica, desdobrados em cartazes, os textos sobre as espécies articulam-se com os variados materiais iconográficos, textuais e 
documentais encontrados em duas principais fontes de pesquisa: em primeiro lugar, no acervo do Herbário Virtual Reflora, que reúne quase 4 milhões de imagens de espécimes da flora brasileira provenientes de herbários nacionais e estrangeiros. Essas amostras de plantas secas - conhecidas como exsicatas - foram entendidas, no guia, como (mais uma) maneira de representação da vegetação, em diálogo com o provocativo slogan oswaldiano de que, no Brasil, "nunca tivemos gramáticas, nem coleções de velhos vegetais” (ANDRADE, [I928] 2008, p. I74)².

2 Com esse slogan, no Manifesto antropófago Oswald parece identificar as gramáticas e as coleções botânicas de plantas herborizadas - “velhas”, guardadas por décadas em empoeirados e inacessíveis arquivos - como formas eurocêntricas e imobilizadas de interpretação da realidade nacional. Para ele, tanto a cultura e a língua, quanto a natureza brasileira trariam o Brasil como uma realidade muito mais complexa, profunda e viva do que tais instrumentos poderiam, em sua pretensa objetividade e universalidade científicas, cogitar. Ainda no próprio Manifesto, outro slogan reforça esse sentido da conexão entre natureza e cultura como elemento da originalidade brasileira: “Contra as elites vegetais. Em comunicação com o solo” (ANDRADE, I928, p. I77). 


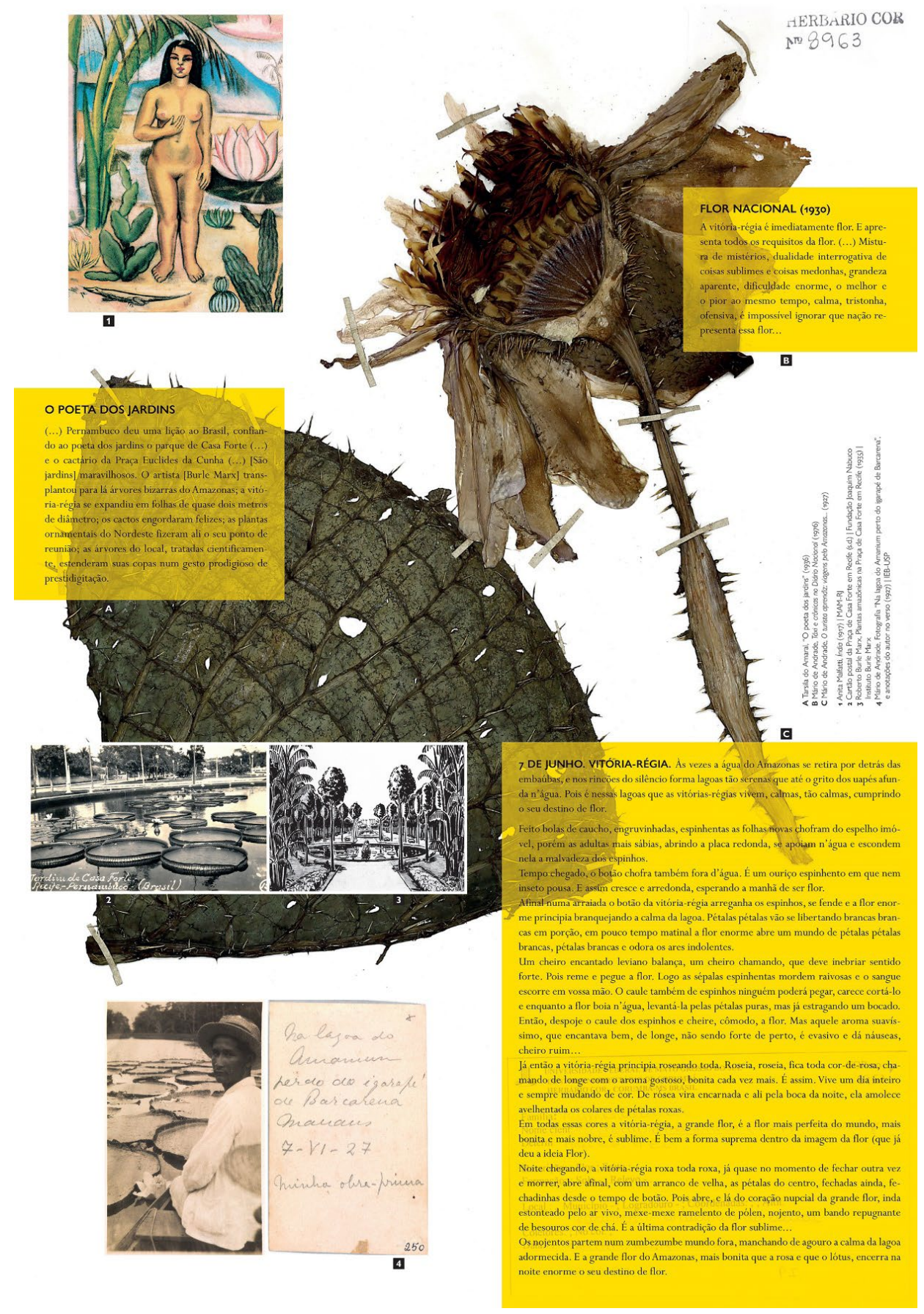

Figura 2 - Pôster do Pequeno guia da botânica modernista: vitória-régia. As obras de Mário de Andrade, Anita Malfatti e Burle Marx são sobrepostas à exsicata da Victoria amazonica, cedida pelo Herbário da Universidade Federal de Mato Grosso do Sul (UFMS) e Projeto Reflora. Fonte: A Autora 
Uma segunda fonte importante - e é sobre ela que nos deteremos aqui - foram os acervos de universidades, museus e outras instituições culturais e de pesquisa, dentre os quais o Museu Lasar Segall, o Centro de Documentação Cultural Alexandre Eulalio da Universidade Estadual de Campinas (Cedae/Unicamp), a Fundação Joaquim Nabuco e o Instituto de Estudos Brasileiros da Universidade de São Paulo (IEB/USP)3. A pesquisa nesses acervos enriqueceu o "levantamento pictórico-literário" inicial; eles revelaram a existência de trabalhos pouco estudados, expostos ou reproduzidos, e, portanto, desconhecidos do grande público. Um exemplo é a produção de Lasar Segall da fase brasileira (entre I924 e I927); apesar de pinturas como Menino com lagartixas (I924) e Bananal (I927) serem amplamente conhecidas, há muitas gravuras e desenhos que o grande público ignora, vários deles estudos sobre a vegetação brasileira, e notadamente sobre a bananeira - que, nelas, ultrapassa a condição referencial de "assunto" para se transformar em "tema plástico" (KLINTOWITZ, I977, p. I02-I03), associando-se à busca de um brasileiro que é popular, negro e feminino. O caso de Tarsila é igualmente emblemático; ainda que as suas pinturas sejam as primeiras a serem lembradas quando se fala em modernismo brasileiro - a exemplo do Abaporu (I928) e seus cactos, ou de Morro da favela (I924) e a vegetação variada que pontua o morro de verde, ajudando a reforçar a visão dos espaços populares como "renitentes imagens de natureza" na cidade (SALZSTEIN, I997, p. I4) -, ainda não foi dada suficiente atenção a muitos de seus interessantíssimos desenhos. Serra da Mantiqueira/Rio Parahyba, por exemplo, é uma das ilustrações de Tarsila que integram a primeira edição de Feuilles de route (I924), de Blaise Cendrars4. Feito durante a viagem a Minas Gerais nesse mesmo ano, esse desenho se revela como um verdadeiro inventário do Brasil "redescoberto", em que a artista, a partir de palavras-chave e registros gráficos rápidos (espalhados pelo papel sem preocupações com relações de escala ou espacialidade), faz um levantamento do repertório pictórico e simbólico que depois será rearticulado em outras obras da fase Pau Brasil: vê-se, assim, uma única figura humana (um homem negro esquemático), construções e elementos construtivos, instrumentos de trabalho, fragmentos da paisagem; a vegetação já se anuncia como elemento central em suas pesquisas, e é constituída por árvores de desenho simplificado, uma pequena embaúba e detalhes de suas folhas, hortênsias, girassóis, uma folha de bananeira, um agave florido, um cacto, cogumelos, uma "parasita" no tronco de uma árvore, outra árvore recoberta de barba-de-velho; as palmeiras aparecem mais de uma vez, e Tarsila está atenta à sua estrutura e à forma como ela se relaciona com a paisagem.

3 Dentre os acervos pesquisados, destacam-se ainda o Arquivo Warchavchik, o Museu da Cidade do Recife, a Coleção de Arte da Cidade do Centro Cultural São Paulo (CCSP), o Sítio Roberto Burle Marx, o Arquivo Público do Estado de São Paulo (Apesp), o Acervo da Floresta Estadual Edmundo Navarro de Andrade (Feena), o Museu Paulista da USP, o Instituto Moreira Salles, o Museu de Arte Moderna do Rio de Janeiro (MAM Rio) e a Pinacoteca do Estado de São Paulo.

4 O IEB possui dois exemplares dessa edição - um pertencente à coleção de Mário e outro à de Yan de Almeida Prado. 
Os acervos também iluminaram a pesquisa ao trazer outros materiais para além das obras artísticas e literárias: fotografias de época, correspondências entre os artistas, manuscritos não publicados, primeiras edições de livros, entre outros documentos. Tais materiais permitiram compreender melhor os significados e problemáticas em torno de cada uma das espécies vegetais; ajudaram a situá-las não apenas em termos da produção artística ou literária, mas também em relação ao contexto histórico, urbanístico, paisagístico em que foram plantadas, descritas, desenhadas; além disso, deram pistas importantes sobre os "lugares" que determinada planta ocupou na biografia de cada artista - por exemplo, os cactos, que, em Tarsila, associam-se à infância na fazenda e, em Flávio de Carvalho, às raízes ancestrais do Brasil (em que o inconsciente encontra-se com a ancestralidade dos povos pré-colombianos). Nesse sentido, no acervo do IEB - que abriga o Fundo Mário de Andrade e o Fundo Anita Malfatti (assim como os arquivos de importantes críticos do modernismo brasileiro, entre eles Gilda de Mello e Souza, Antonio Candido e Aracy Amaral)-, foram encontrados alguns materiais bastante intrigantes, que contribuíram para a proposta do livro de "ir além do livro", abrindo ao leitor a possibilidade de, pelas obras e documentos, reconstituir as formas e sentidos de cada espécie da "botânica modernista”, relacionando-as, inclusive, com a sua própria experiência de vida.

\section{TRÊS FOTOGRAFIAS D'O TURISTA APRENDIZ...}

No arquivo pessoal de Mário de Andrade do IEB, encontramos três fotografias da viagem à Amazônia, realizada em I927 e depois relatada no livro $O$ turista aprendiz: viagem pelo Amazonas até o Peru, pelo Madeira até a Bolívia e por Marajó até dizer chega. Como coloca Telê Ancona Lopez (2005, p. I39), as mais de 500 imagens da viagem ${ }^{5}$ - tiradas com a câmera "Codaque" que o modernista levava a tiracolo -, constituem um verdadeiro "diário imagético", que, acompanhado das legendas a lápis no verso das fotografias, se justapõe ao "diário do texto". O resultado é um diário moderno, fragmentário, multifacetado e híbrido, no qual "viceja tanto o registro que se propõe fidedigno como a criação literária que exerce o humor, o lirismo e a metalinguagem", e onde as “impressões do viajante" se mesclam à “invenção do ficcionista” (LOPEZ, 2005, p. I39).

5 Ainda segundo Lopez (2005, p. I36), o arquivo pessoal do escritor no IEB reúne I.538 imagens em positivo e um grande número de negativos. 

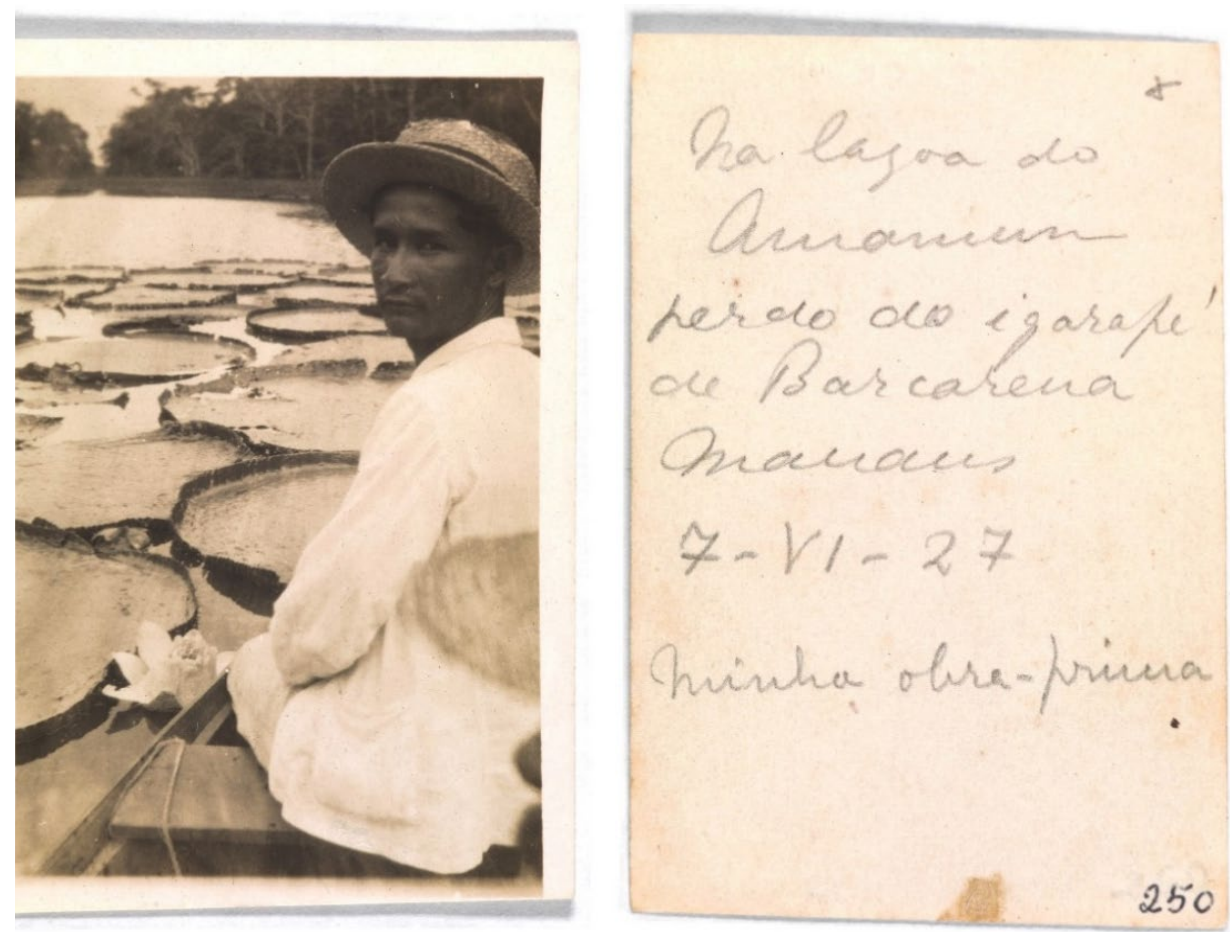

Figura 3 - "Na lagoa do Amanium perto do igarapé de Barcarena Manaus - 7-VI27 - Minha obra-prima”, fotografia e anotações de Mário de Andrade. Fonte: Arquivo IEB/USP, Fundo Mário de Andrade, código de referência MA-F-0250

A primeira dessas fotografias, segundo anotação do próprio Mário, foi tirada em junho de I927 na lagoa do Amanium, em Manaus. Faz parte de uma série de imagens que revelam a "descoberta" da vitória-régia (Victoria amazonica) pelo escritor modernista, demonstrando o seu deslumbramento inicial (equivalente, quem sabe, ao dos primeiros exploradores europeus que descreveram a espécie no século XIX). Em primeiro plano, um pouco deslocado para a direita e olhando para a câmera, aparece o barqueiro, que divide a composição com as enormes folhas flutuantes da planta e a "flor extraordinária" que surge entre elas. Ao fundo, vê-se a superfície da lagoa e as (apequenadas) árvores da floresta. Se, por um lado, essa fotografia ainda retém uma função documental ao se voltar para "os aspectos da geografia física da região [amazônica], para o homem e a cultura material” (LOPEZ, 2005, p. I43), por outro lado, a função poética emerge no enquadramento pouco usual e na ironia da legenda "Minha obra-prima", que parece sugerir certa insegurança do escritor ao se fazer fotógrafo e sua consciência de que a fotografia não deixa de ser uma apropriação da imagem da flor, obra-prima da natureza.

No Pequeno guia, essa imagem liga-se a outras reflexões modernistas sobre a Victoria amazonica: o desenho Índia, de Anita Malfatti, que já em I9I7 resumia a flora brasileira em algumas poucas espécies centrais (como cactos, palmeiras, bananeiras e a vitória-régia), associando-as à figura solene da mulher indígena; o projeto de 
Burle Marx para a Praça de Casa Forte, em Recife, no qual a vitória-régia ocupa lugar de destaque em meio a outras espécies da flora tropical, nos espelhos d'água que estruturam o jardim, logo se transformando em uma de suas principais atrações; e dois textos de Mário que se voltam à planta - uma entrada no diário de viagem à Amazônia, com a mesma data da fotografia (na qual, negando a "vida parada" das naturezas-mortas, cria uma narrativa quase cinematográfica da descoberta da flor, numa sucessão de quadros que desvela os mistérios da flor e os do próprio narrador); e a crônica intitulada “Flor nacional”, publicada no Diário Nacional em 7 de janeiro de I930, na qual avança em sua avaliação acerca do significado dessa planta:

A vitória-régia é imediatamente flor. E apresenta todos os requisitos da flor. [...] Mistura de mistérios, dualidade interrogativa de coisas sublimes e coisas medonhas, grandeza aparente, dificuldade enorme, o melhor e o pior ao mesmo tempo, calma, tristonha, ofensiva, é impossível a gente ignorar que nação representa essa flor... (ANDRADE, [I930] I976, p. I84).

Esse conjunto de textos e imagens não só indica como e quando surge o interesse dos modernistas pela vitória-régia, como demonstra o processo mais amplo de sua transformação em "flor nacional”, um símbolo vegetal contraditório e ambíguo, que traz para o centro do "problema” Brasil uma Amazônia "desgeograficada” e a emergência do feminino como questão, numa associação entre a flor e a mulher que vai além dos clichês acadêmicos (indicando a violência masculina do colonialismo e a força feminina da natureza e dos povos originários que a ele resistem).

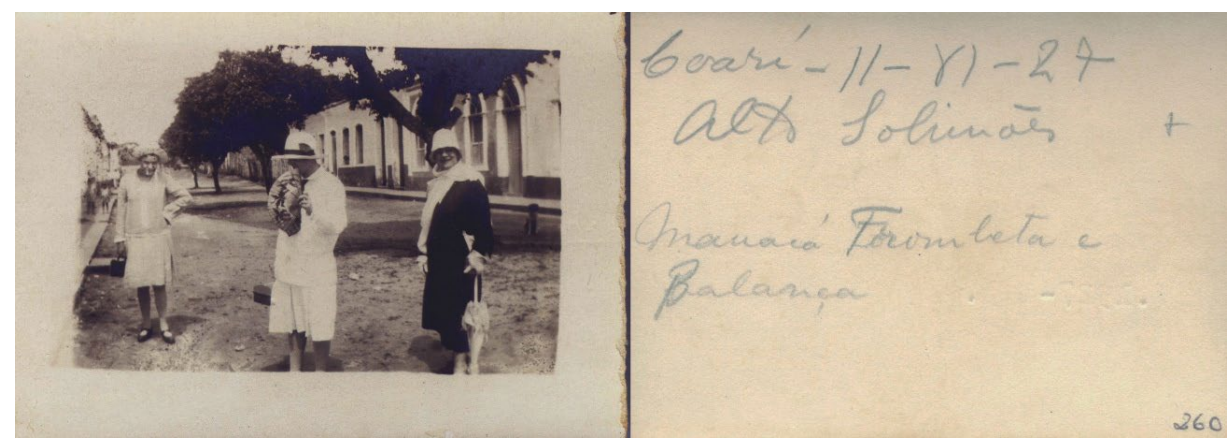

Figura 4 - "Coari-II-VI-27/ Alto Solimões/ Manacá Trombeta e/ Balança”, fotografia de Mário de Andrade. Fonte: Arquivo IEB/USP, Fundo Mário de Andrade, código de referência MA-F-0260

A segunda fotografia de Mário registra suas três companheiras de viagem, d. Olívia Guedes Penteado, Margarida Guedes Penteado (sobrinha de d. Olívia) e Dulce do Amaral Pinto (filha de Tarsila), na legenda identificadas pelos apelidos que o escritor lhes confere durante a excursão: "Manacá, Trombeta e Balança”. 
D. Olívia, objeto da amizade reverente do modernista, é cognominada Nossa Senhora do Brasil e Manacá, flor discreta, perfumada; Dolur se torna Trombeta, e Mag, Balança, por conta de uma brincadeira envolvendo a questão do Juízo Final. (LOPEZ, 2005, p. I42 - grifos nossos).

As três aparecem bem vestidas e sorridentes, em uma rua de chão batido, no pacato município de Coari, no interior do Amazonas. Essa imagem, diferentemente da anterior, refere-se mais proximamente ao que Lopez (2005, p. I42) chama de registro do "cotidiano do quarteto excursionista", que se desdobra "na ficção vivida como lazer". No Pequeno guia, essa fotografia, juntamente com o poema "Carnaval" (I927), faz emergir a dimensão simbólica mais rotineira da árvore manacá, nome popular da Pleroma mutabile (também utilizado para identificar a Brunfelsia uniflora, ou manacá-de-cheiro). Descobre-se assim que, nos anos I920, o nome dessa árvore da Mata Atlântica era também uma gíria que significava mulher bela, faceira, perfumada: “o mocinho vai fuçando o manacá naturalizado espanhola”, diz Mário no poema, jogando com as palavras e nacionalidades e as correspondências entre cultura e natureza. Já o quadro Manacá (I927) de Tarsila amplia essa leitura ao explicitar como, na fase Antropofágica, a visão mais “ingênua” acerca de certas plantas nativas - caso do popular manacá, com suas flores rosas e roxas, que poderiam ser enfeites de papel - radicaliza-se em direção à compreensão de que a natureza, a paisagem e a vegetação estão no centro dos conflitos que permearam a formação do Brasil. $\mathrm{O}$ manacá, assim, funde-se ao cacto, dando origem a uma planta inventada, novíssima e ao mesmo tempo ancestral, que incorpora as dimensões do sonho e do inconsciente para, em sua "extraordinária força explosiva", trazer à superfície sentimentos e sensações longamente reprimidos. 

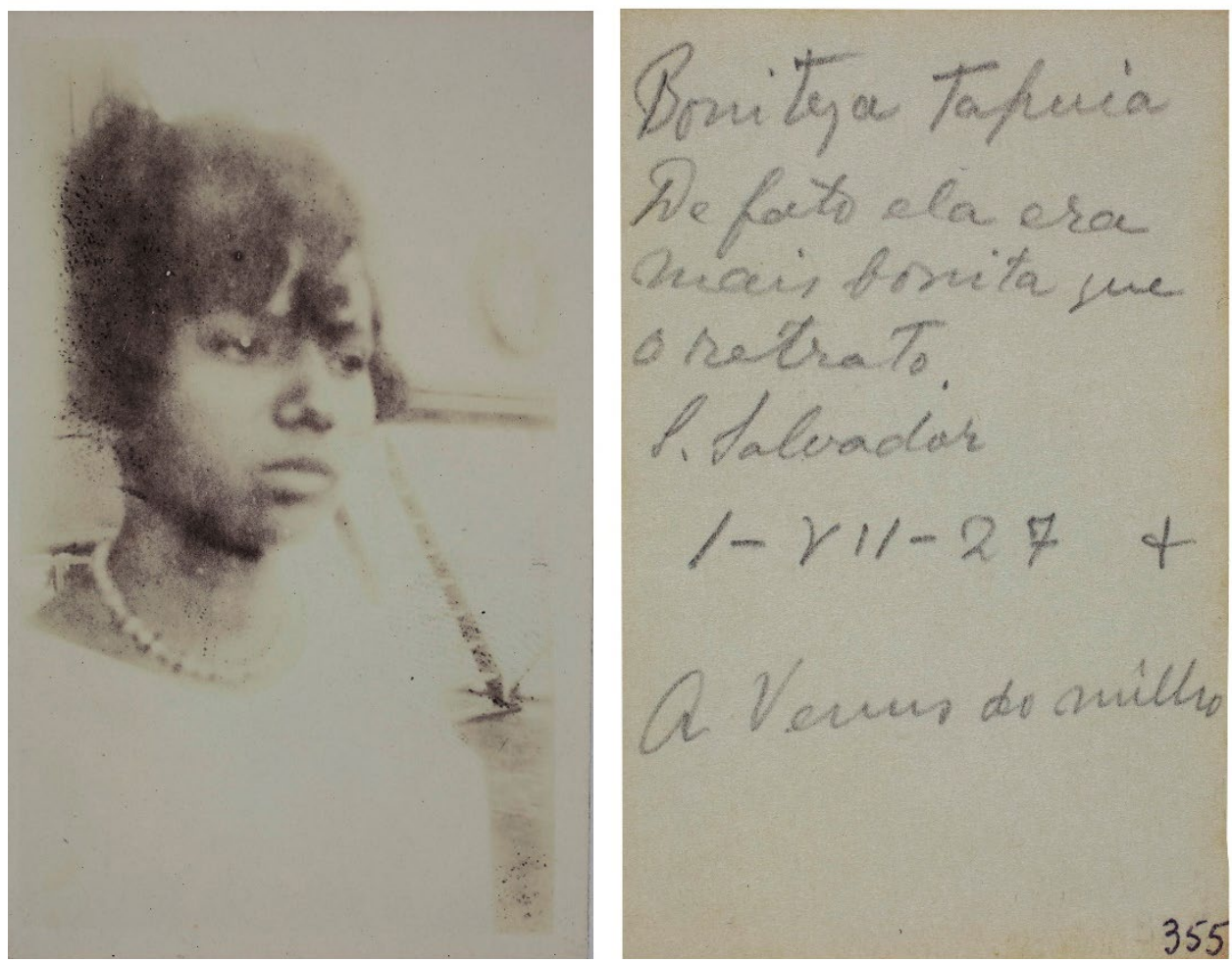

Figura 5 - "Boniteza tapuia - De fato ela era mais bonita que o retrato. São Salvador - I-VII-27 - A Vênus do milho”, fotografia e anotações de Mário de Andrade. Fonte: Arquivo IEB/USP, Fundo Mário de Andrade, código de referência MA-F-0355

A terceira fotografia, a princípio, parece ser um retrato convencional de uma jovem "tapuia" - palavra que os colonizadores usavam para se referir aos índios não tupis do Norte do Brasil e que, ainda hoje, nos estados do Pará e do Amazonas, pode ser usada para se referir a um indígena de qualquer etnia (TAPUIA, 202I). Na legenda, além de identificar a data e local da fotografia, Mário ressalta a "boniteza" da moça, que, numa anotação posterior 6 , faz surgir o trocadilho "Vênus do milho", numa referência à estátua clássica Vênus de Milo, deusa da beleza e do amor. A legenda, tanto pela escolha do termo "tapuia" quanto pelo trocadilho "Milo/milho", ressignifica e transforma a leitura da imagem, fazendo com que ela ultrapasse a dimensão de simples registro etnográfico ou, ainda, de mero registro "sentimental" do viajante - dialogando com a história da arte (além da estátua helenística, pode-se entrever uma possível referência de Mário à Mulher tapuia, do pintor holandês Albert

6 Em relação às legendas anotadas a lápis no verso das fotografias, Lopez (2005, p. I39) explica que em uma primeira etapa da escritura elas "geralmente transpõem apenas as informações colhidas in loco"; em um segundo momento, que pode ser notado pelo traço mais leve, "glosam as representações e o exercício fotográfico”. 
Eckhout, de I64I) e aproximando-a do entendimento da fotografia como linguagem e recurso para a interpretação da realidade brasileira.

A menção ao "milho" (Zea mays), associada à imagem da mulher indígena do Norte do Brasil, ajuda, assim, a compreender o lugar dessa espécie - planta nativa da América e há milhares de anos cultivada pelas civilizações mesoamericanas - na "botânica modernista". Tal compreensão aprofunda-se quando a fotografia é colocada ao lado de outras obras e documentos que fazem referência ao milho - como o bem conhecido poema "Vício na fala", de Oswald de Andrade, ou a fotografia da coleção de Segall que mostra uma casa simples e uma família de trabalhadores rurais em meio a uma roça de milho, ou, ainda, certos trechos de Macunaíma, como “Maioridade”...

[...] Jiguê viu que a maloca estava cheia de alimentos, tinha pacova tinha milho tinha macaxeira, tinha aluá e cachiri, tinha maparás e camorins pescados, maracujá-michira ata abio sapota sapotilha, tinha passoca de viado e carne fresca de cutiara, todos esses comes e bebes bons... (ANDRADE, 20I3a, p. 26).

... e "Ursa Maior":

[...] Taína-Cã deu uma chegadinha no céu, foi até o corgo Berô, fez oração e botando uma perna em cada barreira do corgo esperou assuntando a água. Daí a pouco vieram vindo no pelo da aguinha as sementes do milho cururuca, o fumo, a maniveira, todas essas plantas boas. Taína-Cã apanhou o que passava, desceu do céu e foi no roçado plantar. (ANDRADE, 20I3a, p. 204 - grifos nossos).

No conjunto desses materiais, o que se vislumbra é um reconhecimento do Brasil indígena, negro, caboclo, um país profundo e belo como a linda "Vênus do Milho", onde prevalecem os pequenos roçados, com variadas culturas de subsistência e formas de cultivo tradicionais (como a coivara, em que se intercalam culturas como arroz, feijão e milho). Um Brasil de "vícios" na fala, de gente simples que diz mio e não milho, mió e não melhor, mostrando que a língua é viva e feita na ação cotidiana do plantar, do colher, do construir. Um Brasil que é o inverso do país do café, de fazendas com milhares de hectares e centenas de trabalhadores, domínio da monocultura, do latifúndio e da exportação. Que é originário e original, como as "plantas boas" de Macunaíma.

\section{... E UM CARTÃo-POSTAL}

O último documento do acervo do IEB que aparece no guia é um cartão-postal enviado por Oswald a Mário em 7 de janeiro de I923. Na frente do cartão, uma fotografia colorizada de uma plantação de bananas em Las Palmas, ilha espanhola na costa da África. No verso, ele escreve: "Mário - Bananas! Concorrência ao Brasil! Querem ver que também há modernidade ocidental em Las Palmas - Abraços do Oswald”.

Bananas e bananeiras foram, desde o início da Idade Moderna, identificadas como "exóticas" pelo colonizador europeu, simbolizando, nesse sentido, todo o 
estranhamento do estrangeiro frente às novas culturas e aos territórios longínquos que ele apenas começava a explorar. A partir do século XIX, a expansão imperialista faz com que esse "exótico" se torne econômica e politicamente necessário aos "países centrais" - na medida em que as matérias-primas das zonas tropicais e os "produtos coloniais" (como o açúcar, o chá, o café e as frutas tropicais, entre elas a própria banana) fazem-se essenciais ao desenvolvimento tecnológico e ao estabelecimento da "democracia liberal de massas" nesses países (HOBSBAWM, I998). Nas muitas obras modernistas em que a bananeira se faz presente - como Tropical (I9I7) de Anita, A negra (I923) de Tarsila, várias pinturas e gravuras de Segall, o painel nunca executado de Flávio de Carvalho para o Palácio do Governo do Estado de São Paulo (I928), ou os poemas de Oswald e Mário - veremos que os artistas e escritores, ao olhar constantemente para essa planta, irão lidar com esse ideário do exótico. Ora ele assumirá um sentido positivo (com uma exaltação do Brasil como país dadivoso, de natureza pródiga), ora almejará a superação de tal visão, num esforço de autoconhecimento e mesmo emancipação.

No cartão-postal, a partir da associação entre o bananal e a "modernidade ocidental”, Oswald revela-se capaz de desconstruir a ideia de exotismo - valendo-se, para isso, dos próprios clichês "exotistas". Por meio desse conceito por ele inventado, explicita-se a sua consciência acerca do lugar do Brasil no capitalismo mundial enquanto país exportador de commodities e importador de produtos industrializados e da cultura europeia; ao mesmo tempo, esse lugar é ironizado, criticando-se a ideia de que os brasileiros seriam apenas um outro sem substância própria (uma negação simples da cultura ocidental, europeia e "civilizada"); ele insiste, assim, num autoconhecimento mais aprofundado, sem desconsiderar o caráter integrado e global, desigual e combinado, dessa "modernidade".

O uso dos materiais de arquivo no Pequeno guia significou, portanto, um dos meios para estimular o sentido de descoberta por parte dos leitores do livro - um sentido que, afinal, também movia os artistas de I922. Se para eles a vegetação foi uma das formas de se aproximar do Brasil enquanto "preocupação imperiosa", elemento do "trabalho consciente" de crítica da realidade nacional, como diz Mário (ANDRADE, I924, apud AMARAL, 2003, p. I66-I67), para o leitor atual o contato com esses materiais e linguagens proporciona a abertura necessária para que o caráter "prático, tradicional e experimental" das pesquisas modernistas possa ser não apenas compreendido, mas também vivenciado nos dias de hoje.

Uma imagem sobre os arquivos que nos foi sugerida e muito nos agradou é a de que o Brasil, nas viagens modernistas de "redescoberta", foi uma espécie de arquivo (vivo, acrescentaríamos) para os artistas. Hoje, às vésperas dos Ioo anos da Semana de Arte Moderna, instituições como o IEB guardam uma parte dessa história e dessa produção, milhares ou centenas de milhares de documentos e informações que, como coloca Alberch Fugueras (2003, p. 202), só serão novamente "úteis" quando transformados em conhecimento. Assim, para nós (e, espera-se, para o público leitor), a reunião e a rearticulação dos materiais de acervo, das "velhas coleções" (no dizer de Oswald), contribuiu para a emergência do sentido hodierno da "botânica modernista", 
sem que, entretanto, fosse esquecido o seu sentido original, de forma que, ludicamente, os papéis puderam voltar a ser plantas, e o arquivo, mata, plantação ou jardim.

\title{
SOBRE A AUTORA
}

\author{
ANA CAROLINA CARMONA RIBEIRO é arquiteta \\ e urbanista, doutoranda na área de paisagem e \\ ambiente na Faculdade de Arquitetura e Urbanismo \\ da Universidade de São Paulo (FAU/USP) e professora \\ no curso de Arquitetura e Urbanismo do Instituto \\ Federal de São Paulo (IFSP). \\ accribeiro@usp.br \\ https://orcid.org/0000-0003-3785-I5I4
}

\section{REFERÊNCIAS}

ALBERCH FUGUERAS, Ramon. La dimensión democrática de los archivos. In: ALBERCH FUGUERAS, Ramon. Los archivos, entre la memoria histórica y la sociedad del conocimiento. Barcelona: Editorial UOC, 2003, p. I93-202.

AMARAL, Aracy. Tarsila, sua obra e seu tempo. São Paulo: Edusp/Ed. 34, 2003.

ANDRADE, Mário de. (I928). Macunaíma. Rio de Janeiro: Nova Fronteira, 2013a.

ANDRADE, Mário de. Poesias completas - Vol. I. Rio de Janeiro: Nova Fronteira, 2013b.

ANDRADE, Mário de. (I930). Táxi: Flor nacional. In: ANDRADE, Mário de. Táxi e crônicas no Diário Nacional. São Paulo: Duas Cidades/Secretaria de Cultura, I976, p. I83-I84.

ANDRADE, Mário de. O turista aprendiz. Brasília: Iphan, 2015.

ANDRADE, Oswald de. (I928). Manifesto antropófago. In: SCHWARTZ, Jorge. Vanguardas latino-americanas: polêmicas, manifestos e textos críticos. São Paulo: Edusp, 2008, p. I72-I80.

CENDRARS, Blaise. Feuilles de route. Paris: Au Sans Pareil, I924.

HOBSBAWM, Eric. A era dos impérios (I875-I9I4). Rio de Janeiro: Paz e Terra, I998.

KLINTOWITZ, Jacob. Lasar Segall, um artista contra o caos. In: MILLER, Álvaro et al. Lasar Segall: antologia de textos nacionais sobre a obra e o artista. Rio de Janeiro, Funarte, I982, p. I02-I03.

LOPEZ, Telê Ancona. O turista aprendiz na Amazônia: a invenção no texto e na imagem. Anais do Museu Paulista. São Paulo, v. I3, n. 2, jul.-dez. 2005, p. I35-I64.

REFLORA. Herbário Virtual. Disponível em: http://reflora.jbrj.gov.br/reflora/herbarioVirtual. Acesso em: II jun. 2O2I.

RIBEIRO, Ana Carolina Carmona. Pequeno guia da botânica modernista. São Paulo: Ed. da Autora, 2020.

SALZSTEIN, Sonia. A saga moderna de Tarsila. In: AMARAL, Tarsila. Tarsila Anos 20 [catálogo de exposição]. São Paulo: Sesi, I997, p. 9-I7.

TAPUIA. In: Britannica Escola. Web, 202I. Disponível em: https://escola.britannica.com.br/artigo/tapuia/483582. Acesso em: 24 jun. 202I. 